\title{
Pitched Blade Turbine Efficiency at Particle Suspension
}

\author{
D. Ceres, T. Jirout, F. Rieger
}

\begin{abstract}
Mixing suspensions is a very important hydraulic operation. The pitched six-blade turbine is a widely-used axial-flow impeller. This paper deals with effect relative impeller size and particle content on the efficiency of a pitched six-blade turbine at particle suspension.

Two pitched six-blade turbines were used in model measurements of just suspension impeller speed. The ratios of the vessel to agitator diameter $D / d$ were 3 and 4.5 . The measurements were carried out in a dish-bottomed vessel 300 $\mathrm{mm}$ in diameter. The just suspension impeller speeds were measured using an electrochemical method, and were checked visually. A $2.5 \% \mathrm{NaCl}$ water solution was used as the liquid phase, and glass particles with four equivalent diameters between 0.18 and $0.89 \mathrm{~mm}$ and volumetric concentration from $2.5 \%$ to $40 \%$ were used as the solid phase.

The criterion values $\pi_{s}=P o \sqrt{F r^{\prime 3}(d / D)^{7}}$ were calculated from the particle suspension and power consumption measurements. The dependencies of $\pi_{s}$ on particle content $c_{v}$ show that larger agitators are more efficient for higher particle content.
\end{abstract}

Keywords: Pitched blade turbine, particle suspension, agitator efficiency.

\section{Introduction}

Mixing suspensions is a very important hydraulic operation. Suspensions are frequently mixed when dispersions are prepared or homogenised, and in mass transfer operations between solid particles and a liquid, often accompanied by a chemical or biochemical reaction. It is estimated that about $60 \%$ of mixing involves heterogeneous particulate solid phase-liquid systems.
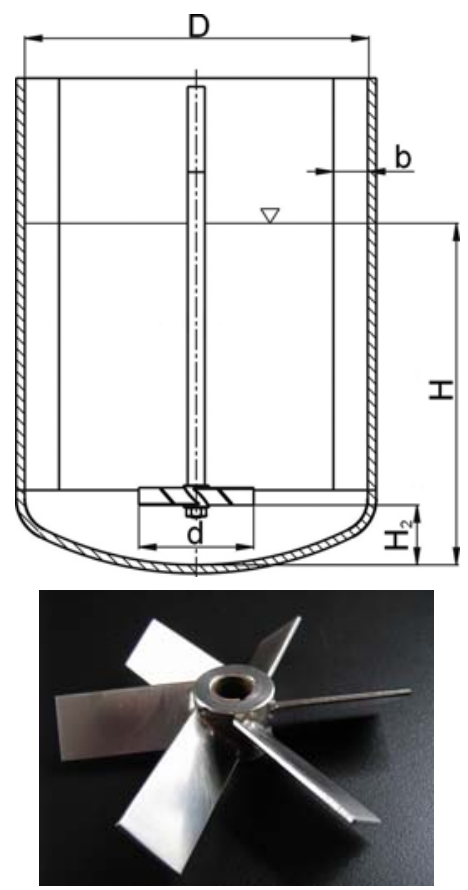

Fig. 1
Numerous papers on particle suspension in agitated vessels have been published. Reviews have been published by Rieger and Ditl [1] and more recently by Kasat and Pandit [2]. These authors show that axial-flow pattern impellers are generally considered the most suitable agitators in such cases. The pitched six-blade turbine shown in Fig. 1 is the one of most widely-used axial-flow impellers. The present paper deals with the effect of relative impeller size and particle content on the efficiency of a pitched six-blade turbine at particle suspension. This problem was also the topic of our earlier papers [3, 4], in which attention was focused on relative impeller size, and measurements were carried out for two particle contents only.

\section{Theoretical background}

In order to design mixing apparatuses, it is important to know the reference state of just off-bottom particle suspension, which is often defined as the state at which no particle remains in contact with the vessel bottom for longer than a certain time. The impeller speed corresponding to this state is referred to as the critical (just-suspended) impeller speed $n_{c}$.

On the basis of inspection analysis of the equation of continuity, the Navier-Stokes equation and the equation expressing the balance of forces affecting the suspended particle, Rieger and Ditl [1] proposed the following relationship linking the modified Froude number $F r^{\prime}$, the dimensionless particle diameter $d_{p} / D$ and the mean volumetric concentration of the solid phase $c_{v}$ 


$$
F r^{\prime}=\frac{n_{c}^{2} d \rho}{g \Delta \rho}=f\left(\frac{d_{p}}{D}, c_{v}\right) .
$$

This relation holds for geometrically similar mixing equipment and a turbulent regime.

The results of critical (just-suspended) impeller speed measurements for the given solid phase concentration $c_{v}$ can be correlated in the power form

$$
F r^{\prime}=C\left(\frac{d_{p}}{D}\right)^{\gamma}
$$

The values of coefficients $C$ and $\gamma$ depend on particle volumetric concentration $c_{v}$. A mathematical description of these dependencies was proposed by Rieger $[5,6]$ in the form

$$
C=A \exp \left(B c_{v}\right)
$$

and

$$
\gamma=\alpha+\beta c_{v}
$$

The dimensionless criterion

$$
\pi_{s}=P o \sqrt{F r^{\prime 3}(d / D)^{7}}
$$

was proposed in [7] for comparing the agitator power consumption necessary for suspension of solid particles.

\section{Experimental}

Two pitched six-blade turbines with pitch blade angle $45^{\circ}$ and blade width $0.2 \cdot d$ were used in model measurements of just suspension impeller speed. The ratios of the vessel to the agitator diameter $D / d$ were 3 and 4.5. The measurements were carried out in a dish-bottomed vessel $300 \mathrm{~mm}$ in diameter. The height of the impellers above the vessel bottom was $0.5 d$. The impellers were operated to pump the liquid down toward bottom of the vessel. The vessels were equipped with four radial baffles $b=0.1 \cdot D$ in width. The height of the liquid level was equal to the vessel diameter $H=D$.

The just suspension impeller speeds were measured by an electrochemical method described e.g. in [8], and were checked visually. A $2.5 \% \mathrm{NaCl}$ water solution was used as the liquid, and glass particles with four equivalent diameters between 0.18 and $0.89 \mathrm{~mm}$ and volumetric concentration from $2.5 \%$ to $40 \%$ were used as the solid phase.

\section{Results}

The dependences of coefficient $C$ and exponent $\gamma$ on the particle volumetric concentration $c_{v}$ for both $D / d$ ratio values were presented in [9]. The plot of exponent $\gamma$ on the particle volumetric concentration $c_{v}$ shown in Fig. 2 shows that it rises linearly with increasing $c_{v}$. The dependence of coefficient $C$ on particle concentration $c_{v}$, see Fig. 3 , shows that the dependences can be approximated in semi-logarithmic coordinates by straight lines. This is in agreement with Eqs. (3) and (4).

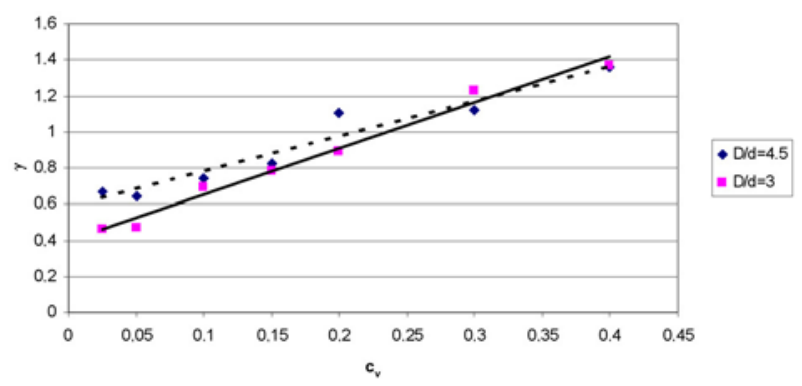

Fig. 2

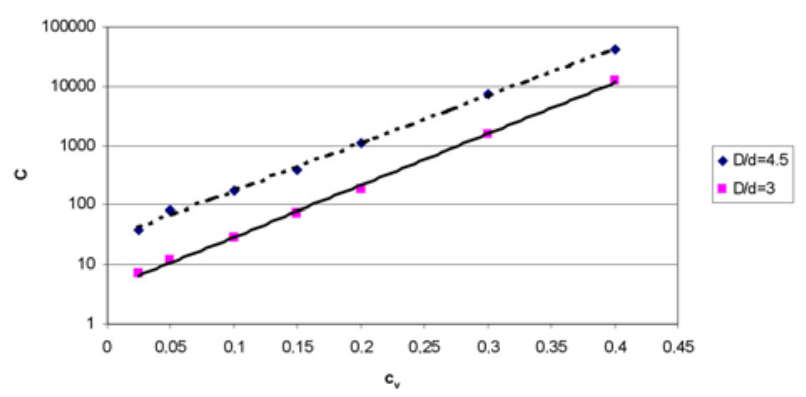

Fig. 3

The values of criterion $\pi_{s}$ were calculated from the results of particle suspension measurements (Eqs. (2-4)) and from the results of power consumption measurements presented in $[7,10,11]$. The results are presented in Figs. 4 and 5. Fig. 4 for smaller particles shows that at low particle content the smaller agitator needs less power for particle suspension, while the converse is true for higher particle content. Fig. 5 shows that for larger particles with low particle content, the two agitators need practically the same power for particle suspension. For higher particle content, the larger agitator is again more advantageous.

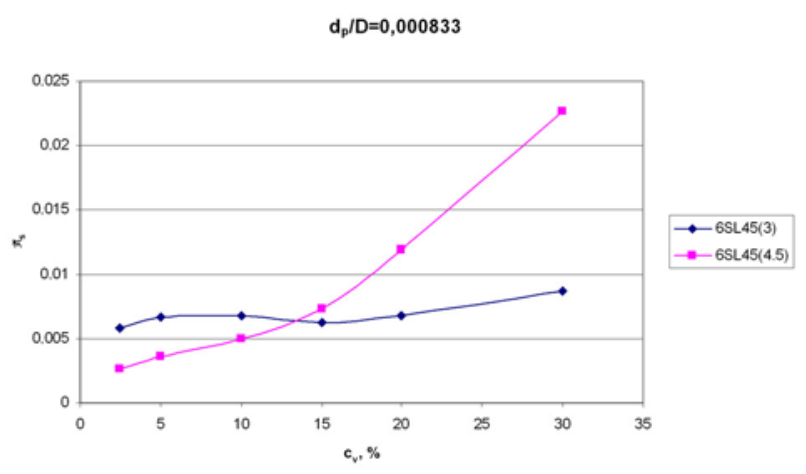

Fig. 4 


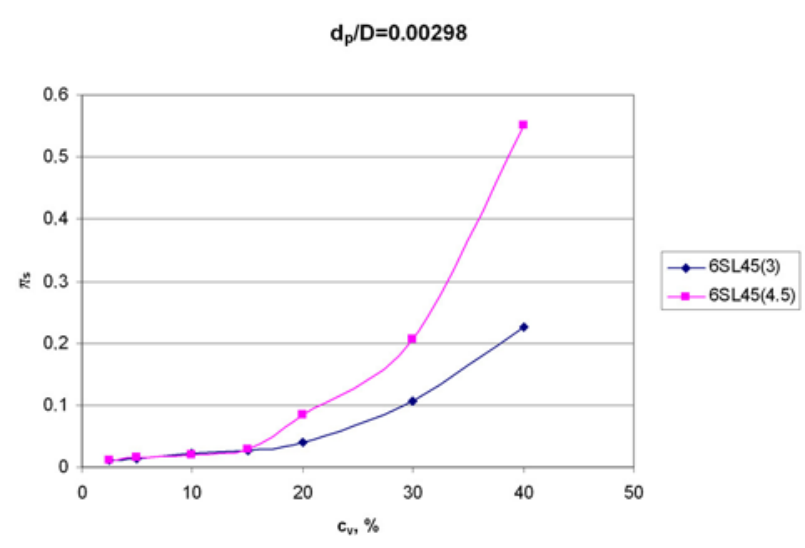

Fig. 5

We can conclude that larger agitators are more efficient for higher particle content. This is in agreement with the conclusions presented earlier $[3,4]$.

\section{Symbols}

$\begin{array}{ll}A, B & \text { constants in Eq. }(3) \\ c_{v} & \text { volumetric concentration of particles } \\ C & \text { coefficient in Eq. }(2) \\ d & \text { agitator diameter } \\ d_{p} & \text { particle diameter } \\ D & \text { vessel diameter } \\ F r^{\prime} & \text { modified Froude number defined by Eq. (1) } \\ g & \text { gravity acceleration } \\ n & \text { agitator speed } \\ n_{c} & \text { critical agitator speed } \\ P o & \text { power number, } P o=\frac{P}{\rho n^{3} d^{5}} \\ \alpha, \beta & \text { constants in Eq. (4) } \\ \gamma & \text { exponent in Eq. }(2) \\ \pi_{s} & \text { dimensionless criterion defined by Eq. (5) } \\ \rho & \text { liquid density } \\ \Delta \rho & \text { solid-liquid density difference }\end{array}$

\section{Acknowledgement}

This project was crried out with financial support from the Ministry of Industry and Trade of the Czech Republic (project number FR-TI1/005).

\section{References}

[1] Rieger, F., Ditl, P.: Chem. Eng. Sci., 49, 2219, 1994.

[2] Kasat, G. R., Pandit, A. B.: Can. J. Chem. Eng., 83, 618, 2005.

[3] Rieger, F., Ditl, P.: Zeszyty Naukowe Politechniky Lódzkiej. Inžyniera Chemiczna $i$ Procesowa. Lódž, Politechnika Lódzka, 1997, 181. ISSN 0137-2602.

[4] Rieger, F., Ditl, P.: The 4th International Symposium on Mixing in Industrial Processes. Toulouse, PROGEP-ISMIP 4, 458, 2001.

[5] Rieger, F.: Chem. Eng. J., 79, 171, 2000.

[6] Rieger, F.: Chem. Eng. Proces., 41, 381, 2002.

[7] Rieger, F.: Proceedings of VI. Polish Seminar on Mixing, Krakow 1993, 79.

[8] Jirout, T., Moravec, J., Rieger, F., Sinevič, V., Špidla, M., Sobolík, V., Tihon, J.: Inż. Chem. Proc. (Chemical and Process Engineering). 26, No. 3, 485, 2005.

[9] Ceres, D., Moravec, J., Jirout, T., Rieger, F.: Inz. Ap. Chem. 49, nr. 1, 25, 2010.

[10] Medek, J.: Proceedings of Czech Conference on Mixing, Brno, 1982, 127.

[11] Ceres, D., Moravec, J., Jirout, T., Rieger, F.: Proceedings of CHISA 2009.

\section{Ing. Dorin Ceres}

Doc. Ing. Tomáš Jirout, Ph.D.

Prof. Ing. František Rieger, DrSc.

Phone: +420224352548

E-mail: frantisek.rieger@fs.cvut.cz

Czech Technical University in Prague

Faculty of Mechanical Engineering

Department of Process Engineering

Technická 4, 16607 Prague 6, Czech Republic 